\title{
Procesos de institucionalización del servicio de capellanía y la asistencia espiritual no católica para hospitales públicos de Argentina
}

\author{
Processes of institutionalization of non-Catholic \\ chaplaincy and spiritual aide in public hospitals of \\ Argentina
}

\section{Gabriela Irrazábal ${ }^{1}$}

${ }^{1}$ Doctora en Ciencias Sociales. Investigadora Asistente, Consejo Nacional de Investigaciones Científicas y Técnicas con sede en Centro de Estudios e Investigaciones Laborales (CONICET-CEIL), Ciudad Autónoma de Buenos Aires, Argentina. $\triangle$ iD
RESUMEN En este artículo nos interesa reconstruir cómo se desarrolla el proceso de institucionalización de un presbiterio de capellanes no católicos para poder adaptarse e interactuar con las instituciones públicas de Argentina, particularmente, las de salud. Para ello, se realizaron entrevistas cualitativas a actores religiosos formados en temas de bioética, observación participante en espacios de formación, congresos y jornadas de bioética y salud y análisis documental de material de estudio y declaraciones de actores religiosos sobre temas de salud y bioética. En un contexto de relaciones de asimetría entre el Estado y las iglesias y pluralización del campo religioso surgen requerimientos de asistencia espiritual diversos en espacios institucionales estatales. En este marco se institucionaliza esta organización de capellanes que desarrolla un ethos propio en búsqueda de reconocimiento, visibilidad y legitimidad social para ofrecer un servicio de capellanía en instituciones donde los únicos capellanes reconocidos y solventados por el Estado pertenecen a la religión católica.

PALABRAS CLAVES Religión; Servicio de Capellanía en Hospital; Terapias Espirituales; Argentina.

\begin{abstract}
This article seeks to reconstruct how the process of institutionalization of a presbytery of non-Catholic chaplains developed as a way to adapt and interact with public institutions in Argentina, particularly health care institutions. For this purpose, qualitative interviews with religious actors trained in bioethics were carried out, in addition to participant observation in training spaces and conferences on health and bioethics and documentary analysis of training material and declarations of religious actors on issues of health and bioethics. In a context of relations of asymmetry between the State and the churches and the pluralization of the religious field, diverse needs for spiritual aide in state institutional spaces arise. It is in such a framework that this organization of chaplains gains institutional status, developing its own ethos in search of recognition, visibility and social legitimacy to offer chaplaincy services in institutions where the only chaplains recognized and funded by the State belong to the Catholic religion.
\end{abstract}

KEY WORDS Religion; Chaplaincy Hospital Service; Spiritual Therapies; Argentina. 


\section{INTRODUCCIÓN}

En este artículo analizamos el trabajo de una asociación civil de carácter religioso que reúne a capellanes evangélicos multidenominacionales. Nos focalizaremos en las actividades que realizan en el ámbito hospitalario en la Argentina, donde los únicos capellanes reconocidos y sostenidos económicamente por el Estado para ejercer su función son los de la religión católica. Consideramos que la formalización de la organización de capeIlanes es resultado de las negociaciones y del reclamo, por parte de religiones minoritarias, de un acceso igualitario al espacio público. La creciente pluralización del campo religioso local ${ }^{(1,2)}$ pone de manifiesto necesidades de asistencia espiritual que no son tenidas en cuenta en el diseño normativo de las instituciones públicas de salud. Esta situación genera tensiones y diversas estrategias de negociación que, a nuestro entender, dieron lugar a la organización de capellanes evangélicos.

En los últimos años ha surgido un creciente interés en las ciencias sociales por el estudio de la intersección entre la religión y la salud y sobre las formas en que la religión es negociada en organizaciones seculares, particularmente, en hospitales ${ }^{(3)}$. Diversos autores han documentado el pasaje de un modelo de capellanías -consideradas como cristianocéntricas- a otro de asistencia espiritual o religiosa multiconfesional(4) $\mathrm{y}$ a una creciente profesionalización de las capellanías hospitalarias ${ }^{(5)}$. En países como EEUU, por ejemplo, abundan trabajos sobre las prácticas de los capellanes y sus niveles de profesionalización ${ }^{(4,6,7)}$. Allí, el trabajo de capellán era voluntario en un comienzo, ya que los ministros atendían y visitaban a los miembros de su congregación. Luego, el cargo de capellán empieza a formalizarse como una profesión en el organigrama de las instituciones hospitalarias, incluso percibiendo un salario. Desde Europa, los estudios se han focalizado más bien en el análisis de la adecuación (o no) de las instituciones públicas a la creciente diversidad religiosa, y en cómo este pluralismo pone en cuestión al propio funcionamiento de estas instituciones y sus distintos modelos de gestión de la diversidad religiosa $^{(8,9)}$. El caso de los capellanes no católicos o multiconfesionales ha sido señalado como un indicador de los roles públicos de las religiones, y también como una reconfiguración del papel del catolicismo en las sociedades contemporáneas que, si bien ve disminuida su incidencia en los entramados de las instituciones públicas, aún ocupa un lugar preponderante ${ }^{(10,11)}$. Desde una perspectiva histórica, algunos autores han señalado las tensiones y dificultades del establecimiento de las capellanías, la laicización del Estado $^{(12,13,14)}$ y las transformaciones en el rol de esta actividad ${ }^{(14)}$.

Desde América Latina también hay un creciente interés por el estudio de las capellanías en distintos ámbitos: empresas, hospitales, cárceles y, en menor medida, las fuerzas de seguridad ${ }^{(15,16,17,18)}$.

Con relación a las capellanías evangélicas, Algranti ${ }^{(19)}$, que estudió este fenómeno en la Argentina, afirma que las iglesias realizan estrategias de acoplamiento institucional. El autor sostiene que los evangélicos intervienen en el ambiente institucional para reconvertir su lógica, sentido y reglas de procedimiento. A partir de allí, comienzan un proceso de reclamo de institucionalización en tanto reconocimiento formal del ejercicio de la asistencia religiosa y una disputa al rol oficial del catolicismo en estos espacios ${ }^{(19)}$.

El binomio formalidad-informalidad del trabajo de capellán en contextos de pluralismo también ha sido abordado por otros autores que han vinculado este fenómeno a la dificultad de constitución y reconocimiento del trabajo de capellán como profesión. En esta línea, De Vries, Berlinger y Cadge ${ }^{(5)}$ han resaltado algunas características de esta tarea que dificultan su reconocimiento como actividad profesional: 1) no tiene una jurisdicción clara y hay desacuerdos sobre las competencias propias de la tarea; 2) existe una autodefinición de personas sin capacitación o certificación como capellanes; 3) hay superposición de tareas con otras profesiones de salud; 4) aparece como un trabajo (el cuidado/asistencia espiritual) considerado 
menor en relación con lo biomédico; 5) existe una representación de teologías particulares (ligadas a grupos o tradiciones específicas); 6) la certificación es otorgada por grupos religiosos o, en algunos casos, por organismos estatales que no cuentan con la validez legal de una licencia o matrícula habilitante para ejercer una profesión (como el caso de las profesiones de la salud). Es interesante que el trabajo de De Vries, Berlinger y Cadge ${ }^{(5)}$ resalta las dificultades de reconocimiento de la profesión del capellán en contextos donde la tarea del cuidado espiritual se encuentra enmarcada dentro de organigramas y frecuentemente solventada económicamente por las propias instituciones de salud. En relación con el trabajo y el rol propios del capellán, Beckford ${ }^{(14)}$ sostiene que ha devenido en un proveedor de confort espiritual, compasión y esperanza fuera del marco de los ministerios parroquiales. Este rol, afirma el autor, es importante para las poblaciones alojadas en instituciones como prisiones, hospitales y cuarteles. Los capellanes, según Beckford ${ }^{(14)}$, son representantes de las religiones que ofrecen servicios espirituales a las personas que viven o trabajan en el marco de instituciones seculares.

El caso argentino resulta diferencial porque en los ámbitos donde los capellanes desarrollan sus tareas (hospitales, cárceles, fuerzas de seguridad), el Estado argentino solventa económicamente con un salario de funcionario público a los capellanes de la Iglesia católica. Esta situación es similar en España, como sostienen las autoras Martínez-Ariño et al. ${ }^{(10)}$. Durante 2016, el Estado español destinó 231.000 euros al sostenimiento del arzobispado castrense y sus capellanes, producto de normativa derivada del concordato firmado con el Vaticano en 1953 y $1979^{(20)}$

Siguiendo a Algranti(21), se pueden diferenciar dos tipos de capellanías. encontramos una capellanía informal o de oficio y una capellanía de función correspondiente al mundo católico. La capellanía de función se caracteriza, según el autor, por la escasez de vocaciones sacerdotales para el trabajo de capellán (en tanto "Ilamado"), la postulación para la tarea mediante un incentivo económico y una restringida capacidad de acción a nivel institucional para fomentar cambios. Por el contrario, para Algranti ${ }^{(21)}$ la capellanía de oficio dentro del mundo evangélico presenta una abundancia de vocaciones (en tanto "llamado") de personas que están dispuestas a desarrollar la tarea de capellán conociendo sus particularidades y su informalidad: ausencia de remuneración y reconocimiento estatal. Para Algranti ${ }^{(21)}$ esta informalidad puede ser interpretada de manera positiva, en tanto permite un espacio de acción amplio para los actores involucrados ya que no existe una obligación contractual con la institución estatal, a diferencia de los capellanes de "función".

Martínez-Ariño et al. ${ }^{(10)}$ indican que existe un proceso incompleto de desmonopolización de los servicios de capellanías en España. Por un lado, se observa que el catolicismo no constituye la única opción disponible de asistencia espiritual para las personas alojadas en prisiones $u$ hospitales $y$, agregamos, en fuerzas de seguridad. Por el otro, las normativas, la negociación y organización de los espacios de culto y el acceso a las instituciones continúan evidenciando una posición de privilegio del catolicismo ${ }^{(10)}$. En un contexto de presencia de otros grupos religiosos y demanda de las personas por asistencia espiritual no católica, los capellanes católicos renuevan su rol y lo moldean de manera estratégica en función de las oportunidades que les otorga su experiencia histórica en los entramados institucionales. El conocimiento del funcionamiento de las instituciones públicas permite a los capellanes católicos desarrollar cuatro roles, según Martínez-Ariño y Griera ${ }^{(22)}$ ofrecen cuidado espiritual y religioso, proveen servicios propios de áreas sociales del Estado, se posicionan como expertos en temas de diversidad religiosa y solucionan problemas cotidianos del día a día de las instituciones. Los capellanes católicos además de actualizar y adaptar sus roles también generan estrategias de resistencia hacia los nuevos grupos religiosos ${ }^{(22)}$.

Así, los estudios de ciencias sociales sobre los capellanes han iluminado los debates sobre las relaciones iglesia-Estado, la laicidad y los procesos de secularización en nuestras sociedades. Existen diversos trabajos que 
abordan de manera individual cada institución en la que se desempeñan capellanes ${ }^{(19,23)}$ y otros que comienzan a realizar un aporte comparativo cross-institutional, analizando los puntos comunes y divergentes entre hospitales y prisiones a la hora de ocuparse de la diversidad religiosa ${ }^{(22)}$.

Nuestra mirada se centra en el proceso inverso. No nos centraremos en cómo las instituciones públicas se adecúan o manejan la diversidad religiosa o cómo el catolicismo adapta sus roles en un contexto de recomposición de creencias. Intentaremos poner la mirada en cómo se desarrolla un proceso de institucionalización de un presbiterio de capellanes no católicos para poder interactuar con las instituciones públicas de Argentina, particularmente, las de salud. Consideramos que los requisitos formales para el acceso a las instituciones hospitalarias en Buenos $\mathrm{Ai}$ res, que cuentan con un Reglamento de las funciones, derechos y obligaciones de los capellanes y congregaciones religiosas en los hospitales municipales ${ }^{(24)}$, favorecen los procesos de institucionalización y formalización de organizaciones de capellanes no católicos. El texto está organizado de la siguiente manera: en primer lugar, describiremos la metodología utilizada en la investigación que da sustento a este artículo; en segundo, indicaremos el contexto geográfico donde se realiza el trabajo y la relación iglesia-Estado en este ámbito; luego, presentaremos los resultados, los que se ponen en discusión en el último apartado.

\section{MÉTODOS}

\section{Localización del estudio, diseño muestral y análisis de datos}

Este artículo es parte de un proyecto de investigación titulado "Religiones y salud. Trayectorias, representaciones y modos de intervención en el espacio público de agentes religiosos formados en bioética en Buenos Aires, Argentina" financiado por el Ministerio de Ciencia y Tecnología de la Nación (2014-2017). Este proyecto tiene un diseño metodológico inscripto en la combinación de técnicas de investigación dentro del paradigma interpretativo de las tradiciones cualitativas $^{(25)}$.

Las técnicas utilizadas incluyen la entrevista cualitativa a actores religiosos formados en temas de bioética; la observación participante en espacios de formación, congresos y jornadas de bioética y salud; y el análisis documental (material de estudio y declaraciones de actores religiosos sobre temas de salud y bioética). La investigación contempla una estrategia de muestreo teórico, gradual, en la que las elecciones de casos se toman en el proceso de recolección de datos según puedan aportar nuevos conceptos y categorías teóricas. Por las características flexibles de los diseños cualitativos, el tamaño final de la muestra se define de manera inductiva y por criterios teóricos a lo largo del trabajo de campo $^{(26)}$. El diseño muestral incluye un total de 12 espacios relacionados con la salud y la bioética de grupos religiosos que participaron de la primera comisión nacional de bioética -experiencia de 1999 y de 2017- y que comprende tradiciones religiosas que tienen participación en el campo de la salud y que no son frecuentemente convocadas a espacios oficiales de bioética y salud como evangélicos pentecostales, testigos de Jehová, mormones y musulmanes. En cada uno de estos espacios se han relevado documentos y realizado entrevistas. En este artículo nos centraremos en el caso del Presbiterio Asociación de Capellanes Argentinos (con predominio de cristianos pentecostales y evangélicos de otras denominaciones) y el principal insumo es una entrevista biográfica realizada a su director general. Además, se analizaron documentos y reglamentos de constitución de la organización y del curso de formación de capellanes (reglamento de funcionamiento, código de ética, curso de capellanes sobre normas de seguridad, protocolo interno, consejería y sanidad interior), se observó la ceremonia de ordenación de siete capellanes y cinco actividades académicas de formación llevadas adelante por capellanes (en universidades y asociaciones médicas) y se realizaron cinco entrevistas a 
capellanes. Todas las actividades se realizaron con el consentimiento informado de las personas involucradas y la autorización del director general de la asociación, por ello se utiliza el nombre real del Presbiterio. Las entrevistas fueron abiertas y se centraron, principalmente, en las trayectorias socioreligiosas individuales y las características de la organización y la tarea específica de la capeIlanía (como profesión).

Para este artículo se utilizan extractos de la entrevista con el director general para ilustrar los principales hallazgos (y no del resto de los entrevistados o del material de las observaciones). Esta decisión se justifica en que, por un lado, el director es el fundador de la Asociación de Capellanes, sin su llamado vocacional no existiría ni se sostendría en el tiempo este grupo de capellanes, su voz resulta relevante para conocer cómo se instalaron las capellanías desde sus orígenes. Por el otro, atendiendo a la dinámica de funcionamiento de la organización, la voz del director, según la división del trabajo interno, es la única autorizada para acceder al espacio público. Se entendió que la publicación en una revista científica es participar del espacio público y por ello los extractos utilizados son solo los de este entrevistado. Esta investigación adopta una perspectiva ética y de epistemología dialógica de co-construcción del conocimiento $^{(27)}$. Por ello, luego de las entrevistas se ha realizado un intercambio con la organización y este artículo, a su vez, fue trabajado con los miembros de la organización previo a su publicación. Desde este enfoque intentamos dar cuenta y respetar la perspectiva del actor. Esta es, según Guber ${ }^{(28)}$ el universo de referencia compartido que subyace y articula el conjunto de prácticas, nociones y sentidos organizados por la interpretación y actividad de los sujetos sociales. Como investigación de enfoque cualitativo, este artículo no pretende generalizar, sino que pone énfasis en profundizar un fenómeno local y micro ${ }^{(29)}$.

La investigación se realiza en Argentina, en el Área Metropolitana de Buenos Aires. Con un $69 \%$ de católicos, esta región cuenta con la menor cantidad de católicos respecto de otras regiones del país, y la mayor cantidad de ateos, agnósticos y sin religión con un $18 \%$, según los últimos datos cuantitativos existentes $^{(1)}$. Los evangélicos en esta región alcanzan el 9,1\%, cifra similar al resto del país ${ }^{(1)}$.

\section{RESULTADOS}

\section{Paisaje religioso y relaciones iglesia- estado en la argentina}

Encuestas recientes señalan el decrecimiento de la afiliación al catolicismo junto con el aumento de individuos que se reconocen evangélicos o indiferentes hacia lo religioso (desafiliados, agnósticos o ateos) en América Latina $^{(2)}$. Asimismo, estudios sociales han destacado el desarrollo de expresiones de la religiosidad popular y nuevas corrientes de espiritualidad ${ }^{(29,30)}$.

En la actualidad, Latinoamérica alcanza un $69 \%$ de católicos, $19 \%$ de protestantes (históricos, pentecostales y neopentecostales) y el $8 \%$ de desafiliados ${ }^{(2)}$. Este panorama se repite en la Argentina, donde los estudios sociales indican que los católicos alcanzan entre un $71 \%$ y un $75 \%{ }^{(2,32)}$. Estas cifras ilustran un decrecimiento del catolicismo del orden del $20 \%$ desde 1970 hasta la actualidad ${ }^{(2)}$, situación que se replica en el Área Metropolitana de Buenos Aires, donde hemos realizado nuestra investigación. Las transformaciones en el paisaje religioso del país, especialmente desde el restablecimiento de la democracia argentina en 1983, han dado lugar a una abundante producción de investigaciones, aunque aún se observa la necesidad de seguir profundizando sobre la diversidad de prácticas y creencias religiosas ${ }^{(31)}$. En general, estas transformaciones en el paisaje religioso han sido interpretadas como un proceso de secularización que implica mayor pluralización, recomposición de creencias y quiebre del monopolio católico ${ }^{(34)}$. Asimismo, se ha indicado que la creciente diversidad no implica mayor pluralismo y que ha aumentado la intolerancia hacia algunas creencias y prácticas religiosas, y se han establecido nuevas estrategias sociales y gubernamentales de regulación de la religión ${ }^{(35)}$. 
Existe consenso en la literatura en considerar que la mayor diversidad religiosa a nivel societal en la población argentina no ha traído aparejado un tratamiento igualitario a todos los cultos a nivel Estatal, configurando un modelo de laicidad subsidiaria ${ }^{(36)}$. Si ponemos el foco en la normativa vigente, encontramos una serie de leyes y ordenanzas estatales que otorgan un lugar de privilegio a la Iglesia católica. El Artículo $2^{\circ}$ de la Constitución de la Nación Argentina indica que el Estado argentino sostiene el culto católico, y el Código Civil de la Nación otorga a la Iglesia católica el estatus de persona jurídica pública junto con los Estados provinciales y municipales y los Estados extranjeros y organizaciones de derechos internacional público (Art. 33 y 34). Asimismo, el Estado argentino otorga un salario a los obispos (arzobispos y prelados) de la Iglesia católica equiparable al $80 \%$ de un juez de primera instancia ${ }^{(37)}$, alrededor de $\$ 3.700$ dólares mensuales en la actualidad. Además, el Estado otorga una asignación mensual a los sacerdotes de zonas de frontera o desfavorables ${ }^{(38)}$ y a los seminaristas que estudian para recibirse de sacerdotes $^{(39)}$. Según Sohr ${ }^{(40)}$, el presupuesto del país aprobado por el parlamento nacional para el año 2016 destinó \$134 millones de pesos (aproximadamente $\$ 8.121 .000$ dólares estadounidenses) para hacerse cargo del sostenimiento de 132 obispos y arzobispos, 568 sacerdotes y 1.120 seminaristas. Además de estas cuestiones, la Iglesia católica recibe transferencias de dinero para el subsidio de sus escuelas y cuenta con exenciones impositivas específicas. Según Prieto ${ }^{(41)}$, en la Argentina, el $96 \%$ de las escuelas privadas confesionales son católicas. Los obispos, además, cuentan con estatus de diplomáticos ${ }^{(42)}$.

Esta serie de regulaciones, que otorga ventajas comparativas en cuanto al sostenimiento económico de la Iglesia católica romana, se complementa con el reconocimiento estatal a las religiones o cultos no católicos. Así, la Ley 21745 de 1978 establece el Registro Nacional de Cultos por medio del cual las organizaciones religiosas (a excepción de la Iglesia católica romana) deben acreditar el tipo de actividad que realizan, su historia, su acta de constitución como organización, certificados de estudios teológicos de los ministros/pastores, características del culto, entre otros requisitos ${ }^{(43,44)}$. Para cualquier tipo de interacción con el Estado e instituciones públicas, se solicita la participación de cultos reconocidos oficialmente. Con relación al tema que nos compete, las capeIlanías, la normativa referida a las fuerzas armadas, las policías, los aeropuertos y los hospitales incluye la figura de la asistencia religiosa a través de capellanes católicos romanos que perciben un salario de funcionario público ${ }^{(42)}$. En Buenos Aires, jurisdicción en la que realizamos este estudio, los capellanes son nombrados por el Estado local y sus cargos se comunican a través del Boletín Oficial del gobierno. Según indica el reglamento de hospitales ${ }^{(24)}$ los capellanes además, son los encargados de regular el ingreso de representantes de otras religiones para visitar pacientes por asistencia espiritual ${ }^{(24)}$ realizando una especie de brokerage (intermediación/corretaje) tal como indican Beckford y Becci para el Reino Unido y Alemania(45,46).

Esta situación de asimetría ha generado diversos debates sobre la libertad religiosa en Argentina que se encuentra garantizada por la Constitución Nacional. En la última década hubo presentaciones de proyectos de ley sobre las implicancias de la libertad religiosa con una fuerte participación e involucramiento de iglesias evangélicas ${ }^{(47)}$. En la actualidad, se está discutiendo en el parlamento argentino un proyecto de ley sobre libertad religiosa que no modifica la situación de asimetría entre la Iglesia católica y las demás religiones ${ }^{(48)}$.

El campo evangélico en la Argentina, en este contexto de relaciones Iglesia-Estado que generan situaciones de asimetría y desigualdad entre los cultos, se ha desarrollado con etapas de mayor crecimiento en distintos momentos históricos desde fines de siglo XIX ${ }^{(49)}$. A partir de la década de 1980 y, en especial, desde la apertura democrática, con particular auge desde la década de 1990, se da una reconfiguración pentecostal del mundo evangélico. Se observa un crecimiento de fieles mediante procesos de conversión, 
transformaciones en el estilo y estética de las prédicas y liturgias y otorgamiento de un marco de interpretación y sentido a crisis sociales y formas de sufrimiento resultantes de la aplicación en la Argentina de políticas neoliberales, según indica Mosqueira ${ }^{(49)}$.

Desde una posición de subalternidad en su relación con el Estado, las religiones no católicas moldean prácticas diferenciadas entre las religiones minoritarias para brindar asistencia espiritual a las personas que lo requieran dentro de instituciones seculares. Consideramos que la formalización de la organización de capellanes constituye una respuesta a esta situación de asimetría y es el resultado de las negociaciones y del reclamo un acceso igualitario al espacio público por las religiones minoritarias.

\section{Estructura organizativa del servicio de capellanía: institucionalización y reconocimiento}

El Presbiterio Asociación de Capellanes Argentinos se constituye en 2015 como una organización dentro de una fundación cristiana. Las fundaciones son entidades a las que el Estado reconoce como personas jurídicas. Legalmente, se encuentran enmarcadas dentro de la categoría de organizaciones de la sociedad civil (tercer sector, organizaciones no gubernamentales) reconocidas, autorizadas y reguladas por el Ministerio de Justicia y Derechos Humanos de la Nación. Para funcionar como tales ${ }^{(50)}$, las fundaciones deben contar con un capital inicial (actualmente unos $\$ 4.000$ dólares), presentar estados contables, balances, nómina de miembros, autoridades y estatutos de funcionamiento anuales. El Presbiterio cuenta con un reglamento y estatuto de funcionamiento que indica quiénes son sus autoridades, cómo se eligen, cuánto dura su mandato, cuáles son sus obligaciones y tareas. En 2017, el Presbiterio se constituyó como una organización no gubernamental independiente. Realizaron los trámites pertinentes para el reconocimiento de su personería jurídica como asociación civil ante el Ministerio de Justicia y Derechos Humanos de la Nación y obtuvieron un número de ficha en el Registro Nacional de Culto que los posiciona como un culto oficial reconocido por el Estado.

El Presbiterio cuenta con un consejo directivo compuesto por un presbítero director general, un presbítero subdirector general, presbíteros directores consejeros y un secretario. No hay restricciones de género en el reglamento de funcionamiento, aunque las principales autoridades son varones. Las decisiones del director general (en cuanto al desarrollo y administración general de la organización) se ponen a consideración del Consejo Directivo que podrá aceptarlas o revocarlas. Los cargos del Consejo directivo son vitalicios, y su vigencia se pierde por infracciones al código de ética, renuncia personal o fallecimiento. El Consejo Directivo establece otros cargos como los directores regionales, divididos por las zonas geográficas de incumbencia de su servicio de capeIlanía, los capitanes de equipo que reportan a los directores regionales y tienen un grupo de capellanes a cargo y, por último, los asistentes de capellanes, que realizan la tarea de shadowing de un capellán durante tres meses y este informa si está capacitado y reúne los requisitos para ser incorporado al Presbiterio.

La organización también cuenta con un Comité de Disciplina y Ética compuesto por tres miembros, seleccionados por el director general, que se encargan de evaluar el cumplimiento de las normas y el ethos institucional de todos los miembros del Presbiterio, incluido el director general. Con relación a las tareas, cada capellán propone un plan de acción a sus capitanes de equipo, que luego elevan a los directores, en el que se detallan las instituciones con las que tomarán contacto y la cantidad de días y horas dedicados a la tarea: "este plan no es únicamente un compromiso con las instituciones y con el Presbiterio, sino que es ante todo un compromiso con Dios"(51). La organización entrega a cada integrante capellán una chapa metálica numerada, una credencial con fotografía identificatoria de la persona, su número de documento nacional de identidad y un número de matrícula propia del Presbiterio. 
Asimismo, otorgan una placa de identificación a los vehículos. Todo cuenta con el símbolo del escudo nacional argentino de manera similar a las identificaciones oficiales emitidas por el Estado.

Los símbolos identificatorios junto con la vestimenta de presbítero (camisa gris, negra o azul y alzacuello) que utilizan principalmente los directivos, refuerzan la identidad y la pertenencia a la organización. Asimismo, otorgan visibilidad y posibilitan el reconocimiento de los funcionarios de las instituciones públicas a las que dirigen sus actividades. Se trata de una forma de mostrar hacia el exterior que están ante la presencia de un grupo religioso institucionalizado y formal, con un reglamento y ética que regula sus tareas. Es una forma de ganar visibilidad, reconocimiento y legitimidad. El director general relata esta necesidad de reconocimiento oficial y de formalización del Presbiterio como una organización con personería jurídica a partir de que su propia trayectoria de formación y preparación como capellán en una institución de EEUU no le permitía ejercer sus funciones en la Argentina:

...me dieron educación como capellán y todos los elementos como corresponde.

Fui a hacer el curso, me entregaron la documentación y en la documentación decía "Estado de Florida - Capellán". Parecía una placa del FBI, todo muy lindo, muy vistoso. Pero yo me puse a analizar y descubrí que eso dentro de la República Argentina no tiene ninguna legalidad no tiene ningún indicio de realidad porque no tiene asentamiento en la Argentina. Entonces, por esa razón, durante un período de tiempo estuve viendo que la herramienta de la capeIlanía era muy útil y muy necesaria pero que no estaba bien implementada. Por eso nos pusimos a trabajar con un grupo de hermanos en Cristo, un grupo de ministros, a estudiar este tema y buscando y averiguando llegamos a la conclusión de que lo que necesitábamos era una personería jurídica de carácter religioso. Por lo tanto, Dios nos llevó a

\begin{abstract}
juntarnos con una fundación que tiene personería jurídica religiosa [...] nuestros capellanes son trabajadores voluntarios y con el sostén legal podemos tener una documentación que nos acredita en toda la República Argentina. (Entrevista presbítero director general, 26/9/2016)
\end{abstract}

Por último, en cuanto al reglamento de funcionamiento, todos los miembros del Presbiterio son voluntarios de la organización cristiana que integran, no reciben remuneración por la tarea que realizan, deben solventarla con sus propios medios y deben contribuir con el pago del curso de formación (el monto depende de las posibilidades de cada integrante) que permita solventar las tareas de todo el Presbiterio (cursos, ordenaciones, traslados por todo el país) y una cuota anual de renovación de la acreditación como capellán. A continuación, realizaremos una aproximación al ethos del capellán promovido por la organización que, de no cumplirse, es motivo de expulsión para sus miembros.

\section{Ethos del capellán}

La organización de capellanes cuenta con un reglamento de funcionamiento y un código de ética. Su misión es prestar auxilio a las personas en necesidad en instituciones seculares ${ }^{(51)}$. El principal valor estipulado por el reglamento para los miembros de la organización es la santidad en la vida personal y el perfecto testimonio, siguiendo las enseñanzas de la Biblia cristiana. Cada capellán es incentivado a comportarse de manera tal que, con sus conductas, favorezca las relaciones de la organización con las instituciones seculares. Por ello, se realizan cursos de capacitación y actualización en los cuales los grupos de capellanes se forman en cuestiones técnicas de la capellanía y también espirituales: "cada capellán es integrante de un equipo y no un luchador solitario"(51). Además de las cuestiones relacionadas al compromiso espiritual y religioso con el Presbiterio, cada integrante firma un compromiso en el cual acepta cumplir las normas éticas y reconocer la autoridad de la Junta Directiva de la organización. Además, 
pone a disposición del Presbiterio sus antecedentes penales:

...nuestro código de ética es regla de oro. El que se salió del código de ética se salió de la capellanía. Es muy estricto, no sale fuera de los principios bíblicos que nos guían, pero si indica cómo se hace la aplicación práctica [...] nosotros tenemos capellanes que han pasado en la cárcel, han vivido, han tenido situaciones con la justicia tiempo atrás y bueno nosotros queremos tenerlo registrado, tenemos que tener todo registrado, no es que lo va a descalificar, al contrario. Quizás lo califique mejor porque ya tiene una experiencia de vida que volcar especialmente en el área de capellán, pero tenemos que saberlo, nosotros llevamos un archivo de cada uno en ese sentido. (Entrevista presbítero director general, 26/9/2016)

Las normas éticas de la organización están vinculadas al ejercicio de las tareas de capellán y también a las características personales de quien las realiza. Se trata de que los capellanes eviten comportamientos en su vida privada que puedan poner en duda su "santidad, honestidad, justicia, probidad y respeto por los otros" ${ }^{\prime(52)}$. Con estas acciones, la organización se garantiza el desarrollo de la integridad en la persona del capellán que en el espacio público oficia como un representante del grupo. Los principales valores que emergen del código ética son evitar el daño hacia las personas que asisten, respetar a los otros en sus creencias, aunque sean distintas a las que ellos profesan, no participar en acciones que atenten contra la libertad o la salud de las personas que asisten y evitar influencias o presiones que podrían perjudicar la capellanía. En este punto destacan la importancia de no recibir sumas de dinero o asistencia financiera para realizar sus tareas o establecer relaciones con otras instituciones (políticas, religiosas) que podrían influenciar la dinámica de la capellanía. Según el código de ética:
El capellán da su ministerio de gracia, pues de gracia lo ha recibido. Jamás podrá reclamar ninguna clase de compensación ya sea monetaria o en especies o servicios por el ejercicio de sus actividades como capellán. Este tipo de actos derivarán en la inmediata e irremisible destitución y expulsión del capeIlán. Se considerará una falta gravísima (equivalente a la solicitud de pagos) el incumplimiento de este punto. ${ }^{(52)}$

La recepción de dinero es un tema que surge en las conversaciones, cursos, ceremonias de ordenación. Los capellanes pueden recibir ofrendas u obsequios que deben ser informados al grupo para su archivo, clasificación y distribución. Las ofrendas se reciben a nombre del grupo y no del individuo. Ponen mucho énfasis en que la tarea es voluntaria y que, además, los capellanes deben hacer un aporte para sostener el funcionamiento de la organización. Todos abonan una suma de dinero por el curso de formación y por la renovación anual de la acreditación como capellán. Esta situación de insistencia en la no aceptación de dinero o de influencias de otras instituciones o grupos se relaciona con la necesidad de mantener una imagen pública de la organización que resulte favorable para el ejercicio de la tarea. En general, teniendo en cuenta las relaciones de asimetría de las religiones en la Argentina, los grupos no católicos deben hacer un esfuerzo mayor para posicionarse de manera favorable ante la opinión pública o acceder a derechos ${ }^{(33,53)}$. En este punto, también se encuentran reguladas las comunicaciones públicas que pueden hacer los capellanes, las maneras de expresarse, brindar información en conferencias, charlas, reuniones con autoridades o entrevistas a la prensa. EI discurso público es un bien simbólico que los miembros de la organización cuidan de manera especial. En general, los discursos públicos son llevados a cabo por el director general de la organización y, desde la comisión directiva, se acuerdan los espacios en los que cada capellán puede desarrollarse. En las conferencias académicas sobre temas 
médicos, participan aquellos que tengan esa formación. En las ceremonias de ordenación, algunos capellanes pueden realizar un discurso público y, otros, se encargan de llevar adelante la Iglesia que depende de ese ministerio, en calidad de pastores. Por último, hay una cuestión que resulta importante en este ethos promovido por la institución: el compromiso. Esto es resaltado con relación al sostenimiento económico de la organización por parte de los capellanes, a la característica voluntaria (sin percepción de dinero) de la tarea y también a la presencia y dedicación que deben tener los capellanes con aquellos a los que asisten espiritualmente:

...vos quedas en ir todos los días de 8 a 22 al hospital tal, servicio tal para atender y vos tenés que estar, llueva truene o haya un terremoto. Entonces, ¿por qué es importantísimo este compromiso? Porque la gente va a estar ahí, te necesita. Si vos sos pastor, a lo mejor a esa misma hora te surgió otro tema y no podés estar. Entonces en general los mejores capellanes no son los pastores. (Entrevista presbítero director general, 26/9/2016)

El director general de la organización destaca que la mayoría de los capellanes de la organización son feligreses que no tienen responsabilidades al frente de congregaciones o iglesias y esto les permite mayor compromiso con la tarea de la capellanía. En síntesis, los valores que contemplan para la persona del capellán son el bienestar, la atención, la objetividad, la honestidad, la sinceridad, la discreción, la confidencialidad, el voluntariado y el compromiso. Trabajan con estos valores que guían su actividad y creen que de esta forma pueden tener éxito en las interacciones con los funcionarios públicos que les habilitan el ingreso a las instituciones en las que se desempeñan.

El cumplimiento del código ético y de las pautas comunicacionales son cuestiones que se encuentran entrelazadas y que permiten que los capellanes puedan interactuar y relacionarse con las instituciones seculares en las que desarrollan sus tareas. A continuación, abordaremos las características de las tareas implicadas en el servicio de capellanía.

\section{Características de la tarea: formación y certificación para el reconocimiento y la legitimidad del servicio de capellanía}

Los capellanes se consideran a sí mismos como "obreros cristianos"(51). Entienden su tarea como aquella encargada de brindar asistencia y llevar consuelo a las personas que se encuentran atravesando momentos difíciles en su trayectoria personal. Interpretan su actividad como una tarea humanitaria y de misericordia orientada a resolver situaciones de crisis, incluso catástrofes. Además, entienden sus funciones como un acompañamiento a aquellas personas que encuentran en soledad o no tienen familiares que los visiten en las instituciones en las que se encuentran alojados (ya sea hospitales, residencias de ancianos, cárceles o cuarteles).

Teniendo en cuenta que el desarrollo de la religión evangélica en las cárceles de Argentina está en crecimiento ${ }^{(17)}$, las actividades en el ámbito carcelario tienen su propia dinámica y funcionan de manera habitual. En general, en los penales ya hay espacio para el ingreso de capellanes o ministros no católicos por parte de las autoridades penitenciarias. En el caso de los hospitales, debido a las ordenanzas de funcionamiento, el ingreso de miembros de otras religiones suele estar regulado por el capellán católico o bien, solo se accede por expreso pedido de algún paciente particular en horarios de visita para el público general. Cuando una persona solicita asistencia espiritual los profesionales de la salud suelen derivarlo al capellán del hospital que es católico y a sus familiares a las capillas de oración, también católicas. Esta situación de asimetría, que ya venimos mencionando, entre el culto católico y otros, conlleva una dificultad en la tarea de la capellanía. El tema del ingreso a las instituciones requiere, para los capellanes no católicos, de un esfuerzo adicional. En este punto el director de la organización comenta cómo desarrollan 
estrategias para garantizarse el acceso a los hospitales y poder realizar sus tareas:

...cuando un capellán va a un hospital, primero se manda una carta de presentación a las autoridades del hospital, tanto a la dirección general como del servicio al que va dar el capellán. Para que el director vea que va con una representación y que es una persona capacitada y que está con nuestro respaldo. El capeIlán primero tiene que hacer un proceso de reconocimiento del lugar, ver cuáles son las necesidades antes de presentarse como capellán. Es todo un trabajo bien armado y siempre con la idea de que el capellán suma. A un funcionario público le sobran problemas. Si el empleado público ve al capellán como un problema más se lo saca de encima. Si el empleado público ve al capellán como algo que le puede solucionar problemas lo abraza con los dos brazos y lo lleva a su casa. Siempre tenemos que presentarnos como proveedores de soluciones y no como proveedores de problemas. (Entrevista presbítero director general, 29/9/2016)

La importancia de la presentación institucional, del reconocimiento a su función y que las autoridades conozcan que se trata de una organización formalizada en el marco de una organización (asociación civil) inscripta en el Ministerio de Justicia resulta central para la realización de la tarea. Tener un respaldo y una acreditación de la formación en la capellanía aparecen como dos elementos centrales a la hora de comenzar el diálogo con las autoridades de las instituciones públicas a las que se dirigen.

La formación y la capacitación a la que hacen referencia es la que da la organización misma. Los cursos son impartidos por el presidente de la organización en colaboración con docentes especializados en las áreas de incumbencia de la capellanía. Tal como sostienen De Vries y Cadge ${ }^{(5)}$ la certificación es otorgada por los propios grupos religiosos y esta no cuenta con la validez legal de una licencia o matrícula habilitante para ejercer una profesión como el caso de las profesiones de la salud. Sin embargo, en la organización hacen mucho foco en la capacitación, al punto de que es obligatoria y está contemplada en el código de ética y el reglamento. También realizan acuerdos con asociaciones médicas para que las capacitaciones tengan una certificación expedida por organizaciones de profesionales de la salud. Los cursos de capacitación ponen el foco en cuestiones ligadas a la pertenencia al Presbiterio (el código de ética, las normas de funcionamiento) y a las características personales del capellán y el cultivo de la sanidad interior. La teología de la sanidad es una formación discursiva que hace referencia a curaciones milagrosas de las enfermedades físicas y también a la expresión interna de la enfermedad en el alma y el espíritu ${ }^{(19)}$. En el pentecostalismo, la noción de persona hace referencia al equilibrio entre el cuerpo, el alma y el espíritu ${ }^{(19)}$. El exterior del individuo está representado por el cuerpo-carne y el cuerpo-comunidad de la Iglesia, el interior (el carácter, los sentimientos, la personalidad) está representada en la noción de alma y el espíritu hace referencia a la presencia de lo sagrado en el interior ${ }^{(19)}$.

Además de cuestiones que podríamos clasificar en el ámbito de lo espiritual/religioso y de pertenencia a la organización, los cursos incluyen normas de bioseguridad, protocolos de ingreso a las instituciones públicas, catástrofes y emergencias y un módulo especial sobre consumo problemático de drogas. Los graduados de los cursos reciben un certificado expedido por el Presbiterio en una unción de capellanes en el marco de una ceremonia del culto dominical en una Iglesia evangélica. Esta varía según la región del país en la que egresen los capellanes. Las graduaciones que observamos para este estudio, entendidas como ceremonias de ordenación y unción, configuraban una ceremonia religiosa en la que el pastor de la Iglesia oficia el culto con su congregación y deja un espacio para los invitados: los capellanes. La unción comienza con unas palabras del presidente del Presbiterio mediante las cuales brinda testimonio sobre su llamado, vocación y 
experiencia como capellán y líder de capellanes. Asimismo, dedica un espacio de su plegaria para comunicarle a la feligresía de la Iglesia en la que se encuentran sobre las características del Presbiterio, las actividades que realizan, la vestimenta que usan los capellanes y los distintos cursos de formación que ofrecen. Se trata también de una convocatoria o reclutamiento de nuevos miembros al Presbiterio que, en la actualidad, luego de casi dos años de funcionamiento, cuenta con 300 miembros. La estrategia de ordenación y unción implica un despliegue territorial, siempre se realiza en distintas Iglesias en distintas ciudades y jurisdicciones. Entendemos este despliegue, además, como parte de las estrategias por el acceso al reconocimiento y la legitimidad. Este reconocimiento no alcanza solo a los funcionarios de las instituciones seculares con las que toman contacto, sino que también se despliega al interior del mundo evangélico. Tal como sostienen De Vries y Cadge $^{(5)}$, las capellanías suelen ser autoadjudicadas por los individuos que las ejercen. Es frecuente encontrar -sostienen los autores- personas que se presentan como capellanes en las instituciones de salud y que no cuentan con una certificación o formación específica para realizar la tarea. La informalidad característica del ejercicio de la capeIlanía en el mundo evangélico ${ }^{(21)}$ permite la existencia de personas que se autodenominan o sus congregaciones los asignan como capellanes para realizar la asistencia espiritual en las instituciones seculares. Esto, como vimos, es una diferencia clara con las capeIlanías de función características del mundo católico ${ }^{(21)}$. En el caso de los hospitales, por las características de funcionamiento y la regulación estatal a la asistencia religiosa, hizo necesario que las capellanías adquirieran un matiz formal, tal como indica el presidente de la organización:

...los pastores se encontraban con el problema de que su acreditación como capellán o como pastor no les permitía entrar a un hospital. Lo que sucede es que había todo este tipo de capellanías informales, no legítimas. No son ilegales, pero no son legítimas [...] Por ejemplo un fichero de culto, un registro de culto no te habilita para una capellanía. (Entrevista presbítero director general, 29/9/2016)

El reconocimiento, la visibilidad y la legitimidad, tanto dentro del mundo evangélico como en el marco de las instituciones públicas a las que se dirigen derivadas de la formación, la estructura organizativa y el ethos de los capellanes resultan centrales para el desarrollo de las tareas de asistencia y cuidado espiritual.

\section{DISCUSIÓN}

En este artículo hemos trabajado sobre la constitución de un presbiterio de capellanes evangélicos que nuclea principalmente a cristianos pentecostales. Por un lado, consideramos que el desarrollo y la institucionalización de esta organización de capellanes es resultado de un reclamo de acceso igualitario al espacio público de las religiones no católicas. Por el otro, es resultado de las prácticas diferenciadas que deben enfrentar para brindar asistencia espiritual dentro de instituciones seculares, debido a las posiciones de subalternidad y las relaciones de asimetría con el Estado. Asimismo, los requisitos formales para el acceso a las instituciones hospitalarias favorecieron este proceso de institucionalización y formalización de la organización de capellanes evangélicos. Esta situación podría entenderse, siguiendo a Roy, como parte de un proceso de formateo (formatting) que Ilevan adelante los Estados hacia las minorías religiosas ${ }^{(54)}$. Este formateo no se produce solo a partir de las leyes y regulaciones específicas, sino también en la alternancia entre el apoyo (en nombre de la libertad religiosa) y la prohibición (en nombre del orden público) de determinadas prácticas religiosas. El formateo, que define y condiciona las prácticas religiosas, es un proceso de interacción y ajustes recíprocos de normas para crear un consenso sobre creencias y 
prácticas aceptables ${ }^{(54)}$. Así como el Estado interviene formateando a las minorías religiosas, coincidimos con Algranti ${ }^{(21)}$ que estamos aquí también ante una estrategia de acoplamiento institucional, una intervención en el mundo de las instituciones seculares para reconvertir su lógica, sentido y reglas de procedimiento. A diferencia de los casos estadounidenses $^{(3,5,6,6,7,8)}$ y europeos $^{(45,46,54,55)}$ el proceso de institucionalización y profesionalización de las capellanías no católicas no implica -aún- un reconocimiento oficial por parte del Estado. Si bien el modelo de asistencia espiritual no ha dejado de ser cristianocéntrico en la Argentina, ya que no encontramos aún modelos de asistencia espiritual multiconfesionales ${ }^{(4)}$ ni tampoco una creciente profesionalización de la tarea de la capellanía ${ }^{(5)}$, presenciamos algunos procesos similares a los hallazgos de las investigaciones realizadas sobre esta temática en los países centrales.

Tal como sostienen De Vries y Cadge ${ }^{(5)}$, la principal dificultad que atraviesan los capellanes es su autocertificación y no reconocimiento estatal de la tarea -a excepción de los católicos como sostienen Martínez-Ariño y Griera ${ }^{(22)}$. Además, no es clara su jurisdicción, cuándo deben intervenir o brindar asistencia ${ }^{(5)}$. Se los suele convocar en momentos del final de la vida ${ }^{(5)}$, ya que es confusa la jurisdicción de la asistencia espiritual como profesión y se superpone con otras disciplinas de la salud como los psicólogos y el servicio social ${ }^{(5)}$. Además, no cuentan con la validez legal de una licencia o matrícula habilitante para ejercer una profesión (como el caso de las profesiones de la salud) teniendo que organizarse jurídicamente como asociaciones civiles para darle un marco de legitimidad a su accionar.

En línea con los análisis de MartínezAriño y Griera ${ }^{(22)}$ podemos observar, a través de las dificultades del trabajo de estos capellanes, que a las instituciones públicas les cuesta manejar la diversidad religiosa. Existe, como sostienen las autoras, un discurso de reconocimiento del derecho a la libertad religiosa y a la solicitud de asistencia espiritual de los pacientes. Es en este contexto que, en general, se convoca a los ministros de religiones no católicas cuando un paciente o sus familiares lo solicitan. Por defecto, cualquier paciente recibirá asistencia espiritual -si lo solicita- de un capellán católico a menos que indique que requiere la visita de un ministro de otra religión. Esta situación nos invita a reflexionar sobre los crecientes grados de diversidad religiosa en la población argentina que no se ven contempladas en las instituciones de salud: los oratorios, los capellanes y los servicios religiosos son católicos. Algranti y Mosqueira ${ }^{(55)}$ realizaron una encuesta a 600 pastores y líderes evangélicos en Argentina y reflejan que en sus iglesias cuentan con capeIlanes para hospitales $(24,5 \%)$. Esto refleja la demanda de la feligresía de recibir asistencia espiritual, la necesidad de recibir formación de estos actores religiosos para tomar contacto con el campo de la salud y la necesidad de seguir profundizando en estudios que den cuenta de las dinámicas de estas capeIlanías tanto en cárceles como instituciones de salud. El crecimiento de estas capellanías podría implicar una salida del modelo de solicitud de capellanes particulares a pedido de los pacientes no católicos a un modelo de asistencia religiosa general o interreligiosa como sostienen estudios recientes en otros contextos $^{(3,4)}$.

Nuestro caso de análisis local y micro(29), el Presbiterio Asociación Capellanes de Argentina, que ha comenzado un proceso de reclamo de institucionalización en tanto reconocimiento formal del ejercicio de la asistencia religiosa y una disputa al rol oficial del catolicismo en estos espacios y a otros agentes del mundo evangélico a los que consideran informales, nos permite también reflexionar sobre las relaciones entre el Estado y las minorías religiosas y los roles públicos de las religiones en Argentina. Particularmente, observamos cómo en el caso español(9,10), una reconfiguración del papel del catolicismo que, si bien ve disminuida su incidencia en los entramados de las instituciones públicas, aún ocupa un lugar preponderante en el ordenamiento legal-normativo y en el desarrollo de las actividades cotidianas de las instituciones a través del brokerage o rol de 
intermediario ${ }^{(45)}$. Por último, la presencia de una organización de capellanes evangélicos multidenominacionales pone en evidencia que las necesidades plurales de asistencia espiritual no son tenidas en cuenta en el diseño normativo de las instituciones públicas de salud en la Argentina y que las religiones no católicas deben encontrar formas alternativas de organización e institucionalización.

\section{CONCLUSIÓN}

La creciente diversidad religiosa de la población argentina no se encuentre reflejada en la gestión y organización de la asistencia espiritual en hospitales públicos. Estas instituciones de salud cuentan oficialmente con capellanes de la religión católica que, como vimos, enmarcan su actividad en normativa gubernamental y perciben un salario del Estado. El rol que asumen los capellanes católicos no alcanza solo a la asistencia espiritual, sino que también administran, intermedian y ponen límites a la diversidad religiosa dentro de las instituciones ${ }^{(9,10,14)}$. La literatura especializada que da cuenta de la pluralización y recomposición de las creencias en la Modernidad ${ }^{(1,32,34)}$ ilustra las demandas crecientes de los creyentes en términos de reconocimiento de la igualdad religiosa ${ }^{(48)}$ y las dificultades que atraviesan las instituciones públicas para dar respuesta a estas demandas ${ }^{(9,10,14)}$. No solo en relación a la asistencia espiritual sino también en la atención asistencial ¿cómo gestionan los hospitales las restricciones de dietas por motivos religiosos?, ¿los tratamientos contrarios a creencias?, ¿la solicitud de terapias alternativas? ${ }^{(56)}$.

En nuestro análisis hemos puesto el foco en el proceso de adaptación de un grupo religioso a los requerimientos normativos de las instituciones públicas de salud. ¿Cómo brindar asistencia y cuidado espiritual a pacientes si sus cuidadores espirituales no tienen reconocimiento oficial del Estado para realizar la tarea? Enfrentándose a la realidad de tener que pedir autorización para cada paciente individual que solicitaba su asistencia y a que ninguna institución reconocía su acreditación como capellán obtenida en EEUU, un pastor evangélico pentecostal funda una asociación civil de capellanes y una escuela de formación para quienes deseen realizar esa tarea. Con esta personaría jurídica logra el reconocimiento de la actividad por parte del Estado y se convierte en un actor que puede entablar comunicaciones oficiales con las instituciones públicas. Los capellanes ya no se dirigen individualmente a los pacientes sino que, como miembros de una asociación civil, entablan contacto con las autoridades hospitalarias para poder realizar su trabajo de manera general en las instituciones, ofreciendo asistencia a todos aquellos que lo necesiten. De alguna manera, compiten con el rol del capellán católico dentro de las instituciones, aunque no pueden celebrar ceremonias en las capillas dado que hay pocas multiconfesionales. Su grado de acción continúa siendo limitado por las estrategias de formateo estatales hacia las minorías religiosas $^{(54)}$. Dentro de este marco limitado, la asociación de capellanes realiza lo que Algranti denomina estrategias de acoplamiento y, a partir de allí, transforma la propia dinámica de las instituciones con las que toma contacto $^{(21)}$

En síntesis, a partir del análisis de la conformación de la asociación de capellanes, podemos concluir que:

- Existen demandas de asistencia espiritual no católica en los hospitales públicos.

- El catolicismo continúa teniendo un papel preponderante en el marco normativo relativo a la asistencia espiritual en instituciones públicas.

- El catolicismo se adapta a la creciente diversidad religiosa, adoptando nuevos roles como el de intermediación y administración de espacios multiconfesionales.

- El Estado formatea a las minorías religiosas a través de estrategias de autorizaciones y prohibiciones ${ }^{(54)}$.

- Las instituciones públicas de salud encuentran dificultades para la gestión de la diversidad religiosa. 
- Las minorías religiosas se adaptan al marco normativo limitante y desarrollan estrategias que transforman las dinámicas de las instituciones de salud.

- Se desarrollan procesos de profesionalización de las tareas de capellanía debido a las demandas de asistencia y cuidado espiritual no católica.

- La profesionalización de los capellanes no católicos es aún incipiente. Primero debie- ron constituirse como un interlocutor válido para el Estado y luego ocuparse de su formación.

Para finalizar, el caso aquí analizado pone en evidencia la necesidad de desarrollar políticas públicas que contemplen el acceso igualitario a la asistencia espiritual de todos los pacientes de hospitales públicos que así lo requieran.

\section{AGRADECIMIENTOS}

Esta investigación fue financiada por el Ministerio de Ciencia, Tecnología e Innovación Productiva (2014-2017) a través del proyecto PICT 2013 2541 "Religiones y salud. Trayectorias, representaciones y modos de intervención en el espacio público de agentes religiosos formados en bioética en Buenos Aires, Argentina", bajo la dirección de la doctora Gabriela Irrazábal. A los miembros del Presbiterio Asociación Capellanes de Argentina (PACA) por su predisposición y colaboración para realizar esta investigación. A los/as evaluadores/as de este texto por sus pertinentes sugerencias que han enriquecido el desarrollo del artículo.

\section{REFERENCIAS BIBLIOGRÁFICAS}

1. Mallimaci F. Atlas de las creencias religiosas en Argentina. Buenos Aires: Biblos; 2013.

2. Esquivel JC. Transformations of religious affiliation in contemporary Latin America: an approach from quantitative data. International Journal of Latin American Religions. 2017;1(1):5-23.

3. Cadge W, Sigalow E. Negotiating religious differences: the strategies of interfaith chaplains in healthcare. Journal for the Scientific Study of Religion. 2013;52(1):146-158.

4. Pais Bernardo L. De la capellanía a la asistencia religiosa: el campo religioso portugués en los hospitales. Sociedad y Religión. 2016;26(46):181200.

5. De Vries R, BerlingerN, CadgeW. Lost in translation: sociological observations and reflections on the practice of health care chaplaincy. The Hastings Center Report. 2008;38(6):23-27.

6. Fitchett G, Tartaglia A, Massey K, Jackson-Jordon $B$, Derrickson PE. Education for professional chaplains: should certification competencies shape curriculum? Journal of Health Care Chaplaincy. 2015;21(4):151-164.

7. Idler EL, Grant GH, Quest T, Binney Z, Perkins MM. Practical matters and ultimate concerns, "doing," and "being": a diary study of the chaplain's role in the care of the seriously ill in an urban acute care hospital. Journal for the Scientific Study of Religion. 2015;54(4):722-738.

8. Goldstein HR, Marin D, Umpierre M. Chaplains and access to medical records. Journal of Health Care Chaplaincy. 2011;17(3-4):162-168.

9. Griera M, Martínez-Ariño J, Clot-Garrell A, Garcia-Romeral G. Religión e instituciones públicas en España: hospitales y prisiones en perspectiva comparada. Revista Internacional de Sociología. 2015;73(3). doi: 10.3989/ris.2015.73.3.e020.

10. Martinez-Ariño J, García-Romeral G, UbasartGonzález G, Griera M. Demonopolisation and dislocation: (re-)negotiating the place and role of religion in Spanish prisons. Social Compass. 2015;62(1):3-21.

11. Schneuwly Purdie M. "Silence... nous sommes en direct avec Allah": I'émergence d'intervenants musulmans en contexte carcéral. Archives de Sciences Sociales des Religions. 2011;(153):105-121.

12. Lalouette J. L'hôpital entre religions et laïcité: du Moyen-Age à nos jours. Paris: Letouzey et Ané; 2006.

13. Guillemain H. L'hôpital et ses religions: pratiques conflictuelles dans les établissements de I'assistance publique de Paris (1870-1914). En: Sainclivier J, Pitou F, editors. Les affrontements: usages, discours et rituels. Rennes: Presses universitaires de Rennes; 2008. p. 147-158.

14. Beckford JA. Prisons et religions en Europe. Archives de Sciences Sociales des Religions. 2011;(153):11-21. 
15. Portales L. El poder de las palabras de los capellanes: el impacto en los colaboradores de la gestión de la espiritualidad laboral. Estudios Gerenciales. 2015;31(135):212-222.

16. Mansilla M. Sociología y pentecostalismo: intereses, énfasis y limitaciones de las investigaciones del pentecostalismo chileno (1990-2011). Civitas. 2012;12(3):538-555.

17. Brardinelli RL, Algranti J. La reinvención religiosa del encierro: hermanitos, refugiados y cachivaches en los penales bonaerenses. Buenos Aires: Centro Cultural de la Cooperación Floreal Gorini, Universidad Nacional de Quilmes; 2013.

18. Prieto S. Religión y espacio público en la Ciudad de Buenos Aires: igualdad de cultos, libertad de conciencia y autonomía en el debate sobre los capellanes y las religiosas en los hospitales porteños. Ada. 2017;(5):125-157.

19. Algranti J. De la sanidad del cuerpo a la sanidad del alma: estudio sobre la lógica de construcción de las identidades colectivas en el neo-pentecostalismo argentino. Religião \& Sociedade. 2008;28(2):179-209.

20. Rejón R. El Estado gastó más de tres millones de euros en los curas e iglesias de las Fuerzas Armadas en 2016 [Internet]. El Diario Es; 2017 [citado 15 ene 2018]. Disponible en: https:// tinyurl.com/yb4haa96.

21. Algranti J. "Cuando ellos tengan dos mil años, hablamos!" Sociología de los capellanes en las cárceles bonaerenses. Questión. 2012;1(36):1-15.

22. Martinez Ariño J, Griera M. Responses to religious diversity in Spain: hospitals and prisons from a comparative perspective. Interdisciplinary Journal for Religion and Transformation in Contemporary Society. 2016;2(1):37-59.

23. Cadge W. Paging god: religion in the halls of medicine. Chicago: University of Chicago Press; 2012.

24. Municipalidad de la Ciudad de Buenos Aires. Ordenanza 38397/82[Internet]. Buenos Aires: Municipalidad de la Ciudad de Buenos Aires; 1982 [citado 1 ago 2017]. Disponible en: https://tinyurl. com/ybtda8uu.

25. Vasilachis de Gialdino I, editora. Estrategias de investigación cualitativa. Barcelona: Gedisa; 2006.

26. Maxwell JA. Qualitative research design: an interactive approach. 3a ed. Thousand Oaks: Sage; 2013.
27. Marková I. Amédée or how to get rid of it: social representations from a dialogical perspective. Culture \& Psychology. 2000;6(4):419460.

28. Guber R. El enfoque antropológico: señas particulares. En: El salvaje metropolitano. 3a ed. Buenos Aires: Paidos; 2009. p. 67-81.

29. Galeano Marín ME. Diseño de proyectos de investigación cualitativa. Medellín: Universidad EAFIT; 2004

30. Míguez D, Seman P, editores. Entre santos, cumbias y piquetes: las culturas populares en la Argentina reciente. Buenos Aires: Biblos; 2006.

32. Viotti N. Emoción y nuevas espiritualidades: por una perspectiva relacional y situada de los afectos. Antípoda-Revista de Antropología y Arqueología. 2017;(28):175-191.

32. Mallimaci F, Esquivel JC, Giménez Béliveau $\mathrm{V}$. What do Argentine people believe in?: religion and social structure in Argentina. Social Compass. 2015;62(2):255-277.

33. Frigerio A, Wynarczyk $\mathrm{H}$. La diversidad religiosa en Argentina: un desafío a la ciencia normal. Religión y Cultura. 2013;7(1):3-9.

34. Mallimaci F, Esquivel JC. Pluralism and individualization in the argentine religious field: challenges for catholicism in the perspective of society and politics. Politics and Religion Journal. 2016;9(1):35-51.

35. Frigerio A. Questioning religious monopolies and free markets: the role of the state, the church(es), and secular agents in the management of religion in Argentina. Citizenship Studies. 2012;16:997-1011.

36. Mallimaci F. Laïcité de subsidiarité en Argentine: entre élargissement des droits sociaux et recherche mutuelle de légitimité. En: Baubérot J, Milot M, Portier P, editors. Laïcité, laïcités: reconfigurations et nouveaux défis (Afrique, Amériques, Europe, Japon, pays arabes). Paris: Maison des sciences de I'homme; 2016. p. 221-252.

37. Argentina, Poder Ejecutivo Nacional. Ley 21950: jerarquía eclesiástica; asignación mensual [Internet]. Argentina: Ministerio de Justicia y Derechos Humanos; 1979 [citado 01 ago 2017]. Disponible en: https://tinyurl.com/y9layz7y.

38. Argentina, Poder Ejecutivo Nacional. Ley 22162: culto Católico Apostólico Romano; asignación mensual. Argentina: Ministerio de Relaciones Exteriores y Culto de la República Ar- 
gentina; 1980 [citado 01 ago 2017]. Disponible en: https://tinyurl.com/yazcpbda.

39. Argentina, Poder Ejecutivo Nacional. Ley 22950: clero diocesano; régimen de sostenimiento de la Iglesia Católica [Internet]. Argentina: Ministerio de Justicia y Derechos Humanos; 1983 [citado 1 ago 2017]. Disponible en: https://tinyurl.com/ y7cds6q7.

40. Sohr O. ¿Cuánta plata le transfiere el Gobierno a la Iglesia para sostener el culto católico [Internet]? Chequeado (Fundación La Voz Pública); 2016 [citado 23 jun 2017]. Disponible en: https:// tinyurl.com/ybn923g3.

41. Prieto S. Religión y transferencia del gasto educativo en las provincias argentinas (19992010). [Tesis de maestría]. Buenos Aires: Universidad Torcuato Di Tella; 2016.

42. Esquivel JC. Cultura política y poder eclesiástico: encrucijadas para la construcción del Estado laico en Argentina. Archives de Sciences Sociales des Religions. 2009;(146). doi: 10.4000/assr.21217.

43. Argentina, Poder Ejecutivo Nacional. Ley 21745 Registro Nacional de Culto [Internet]. Argentina: Ministerio de Justicia y Derechos Humanos; 1978 [citado 1 ago 2017]. Disponible en: https://tinyurl.com/y74ggazs.

44. Catoggio MS. Tensiones históricas en torno al registro de cultos y otras "herencias": libertad fichada. Nueva Tierra. 2011;23(72):37-39.

45. Beckford JA. Prison chaplaincy in England and Wales: from Anglican Brokerage to a Multi Faith Approach. In: Koenig M, De Guchteneire P. Democracy and human rights in multicultural societies. Ginebra: Ashgate; 2007. p. 267-282.

46. Becci I. Imprisoned religion: transformation of religion during and after imprisonment in Eastern Germany. London: Routledge; 2016.
47. Carbonelli MA, Mosqueira MA. Evangélicos y política: tensiones en torno a la libertad e igualdad religiosa en Argentina. Revista Científica GuiIlermo de Ockham. 2012;10(1):41-54.

48. Mallimaci F. Con la conciencia a otra parte [Internet]. Página 12; 2017 [citado 21 ago 2017]. Disponible en: https://tinyurl.com/yb3wuakp.

49. Mosqueira M. "La manifestación de los hijos de Dios": reconfiguración del campo evangélico y emergencia del sujeto juvenil cristiano en la Argentina (1960-2000). Revista de Ciencias Sociales. 2016;8(30):53-83.

50. Argentina. Ley 19836-Fundaciones: régimen para su desenvolvimiento y control [Internet]. Argentina: Inspección General de Justicia; 1972 [citado 1 ago 2017]. Disponible en: https://tinyurl. com/y9afc29a.

51. Presbiterio Asociación de Capellanes Argentinos. Reglamento. Ciudad Autónoma de Buenos Aires: PACA; 2015.

52. Presbiterio Asociación de Capellanes Argentinos. Código de ética. Ciudad Autónoma de Buenos Aires: PACA; 2015.

53. Bianchi S. Historia de las religiones en Argentina: las minorías religiosas. Buenos Aires: Sudamericana; 2004.

54. Roy O. Secularism and islam: the theological predicament. International Spectator. 2013;48(1): 5-19.

55. Algranti J, Mosqueira M. Encuesta a pastores y líderes evangélicos de Argentina (Proyecto PIP 112-201501-00375). Ciudad Autónoma de Buenos Aires: CEIL-CONICET; 2017.

56. Krmpotic C, Zaizar M. Políticas socio-sanitarias y alternativas terapéuticas: intersecciones bajo la lupa. Buenos Aires: Espacio; 2015. 